ISSUES IN DIGITAL CARTOGRAPHIC DATA STANDARDS

\title{
Report \#2
}

Selected Papers from the Session on Digital Cartography - Planning and Standards at the Fifth International Symposium on ComputerAssisted Cartography, Crystal City, Virginia August 23, 1982 .

Harold Moellering, Editor

$$
87 \cdot 302
$$

September 1982

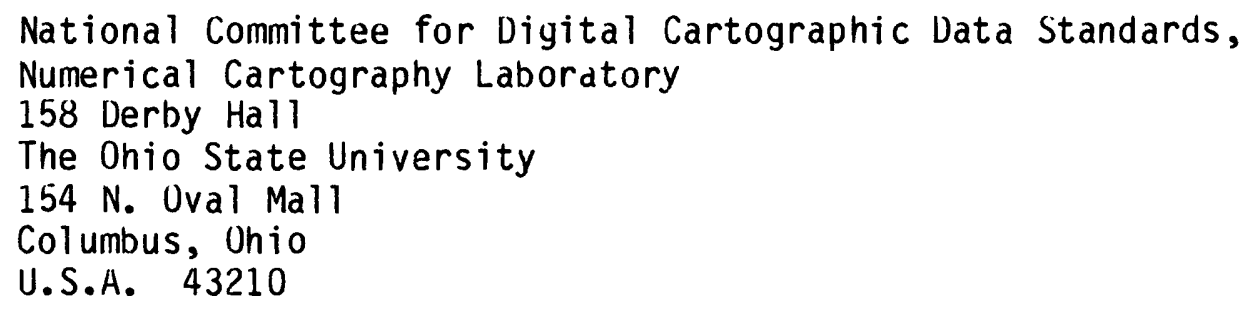

National Committee for Digital Cartographic Data Standards, Numerical Cartography Labordtory 158 Derby Hall

The Ohio State University

154 N. Uval Mall

Columbus, Ohio

U.S.A. 43210

The committee operates under the auspices of the American Congress on Surveying and Mapping. This work of the Committee is being funded by U.S. Geological Survey Grant \#14-08-0001-G-787. Production assistance has been provided by The Unio State University Research Foundation (RF Project 714484). Permission to reprint these papers has been given by the organizers of the Auto-Carto Symposium. 


\section{PREFACE}

This report is the second in a series which discusses the work of the National Committee for Digital Cartographic Data Standards. It contains one paper and four oral reports presented at the session on Digital Cartography - Planning and Standards held at the Fifth International Symposium on Computer-Assisted Cartography at Crystal City, Virginia in August 1982. The paper by Moellering provides a summary of the recent work and current situation of the National Committee for Digital Cartographic Data Standards. The four following reports are the outlines of presentations given in a panel session by members of the Working Groups of the Committee:

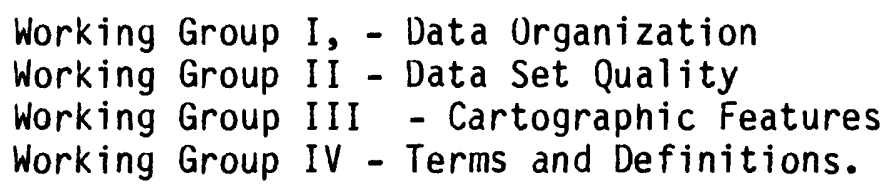

These last four reports represent the current thinking of the members of the Working Groups on the National Committee. Further reports will be provided as the work progresses.

Harold Moellering

Series Editor 
TABLE UF CONTENTS

Page

The Goals of the National Committee for Digital Cartographic Data Standards, by Harold Moellering ............ 1 Report on the activities of Working Group I, Data Set Urganization, by Tim Nyerges, Chairman ......... 9 Report on the activities of Working Group II, Data Set Quality, by Dean Merchant, Member ...........11

Report on the activities of Working Group III, Cartographic Features, by Joel Morrison, Chairman ...........13 Report on the activities of Working Group IV, Terms and Definitions, by Harold Moellering, Coordinator ....... 15 
THE GOAIS OF THE NATIONAL COMMITTEE FOR

DIGITAL CARTOGRAPHIC DATA STANDARDS

by

Harold Moellering

National Cormittee for Digital Cartographic Data Standards

Numerical Cartography Laboratory

158 Derby Hall

Ohio State University

154 N. Oval Mall

Columbus, Ohio 43210

U.S.A.

ABSTRACT

In recent years many indivicuals and groups have been concerned about the lack of digital data standards in cartography for the United States. Although several efforts have attenpted partial solutions to some very narrow parts of the problem no one has initiated a camprehensive effort to address the broad soope of the problem. Several months ago the National Canmittee for Digital Cartographic Data Standards was founded under the auspices of the American Congress on Surveying and Mapping and arganized to begin the task of systematically examining the problem and issues surrounding it. This paper discusses the organization and goals of the National Comittee for Digital Cartographic Data Standards and examines a number of issues associated with this work.

\section{INIRODUCTION}

Recent decades have seen a tremendous growth in digital cartography, Erom a laboratory curiosity to a force that daminates modern cartography. With this growth the field has seen a proliferation of differing and incompatible approaches to acquiring, coding, storing and exchanging cartographic data. It has become clear that the continuing proliferation of differing approaches to the handling of cartographic data could hinder the orderly development of digital cartography. This fact has been clearly recognized and as a result the National comittee for Digital Cartographic Data Standards has been founded to address this problem. The committee operates under the auspices of the American Congress on Surveying and Mapping in ooperation with the U.S. Geological Survey and the U.S. Bureau of Standards. As discussed in an earlier paper by Moellering (1982), the comittee has been given a mandate to address the question of developing standards for digital cartography. This paper discusses the organization of the committee and the goals it has defined to address the problems of digital cartographic data standards.

The conceptual milieu in which the committee is operating has also expanded dramatically in recent years as noted in the earlier paper. The concepts of real and virtual maps greatly clarify the situation of the new digital cartographic products and how they relate to the more conventional products (Mbellering, 1980). Transformations between real virtual maps define most important operations in cartography and have been an interesting concept for the design of modern cartographic systems. Nyerges (1980) has devised the notions of deep and surface structure as they apply to cartographic information and has shown that surface structure representations of cartographic information are real and 
virtual type 1 maps while cartographic deep structure is usually represented in the digital damain by type 3 virtual maps. It is also possible to look at these standards efforts in terms of deep and surface structure. Surface structure is the graphic representation of cartographic information such as a conventional map or CRT display. Over the years many principles have been defined for cartographic design which must be followed if one is to have an effective map. However, the deep structure, that area of spatial relationships between cartographic elements of cartographic information which are not graphic, is where much of the digital information resides which is stored in modern cartographic cata bases. In essence, the primary task of this canmittee is to bring conceptual order to the area of deep structure in digital cartography.

\section{THE WORK OF THE NATIONAL COMMITIEE}

In recent years a number of ad hoc attempts have been made to define local standards for some rather narrow areas of cartography. It turns out that the groups which have attempted such efforts have done so out of necessity to implement specific tasks rather than a desire to solve a general problem in digital cartography. However, the approach of the cormittee is to take a comprehensive look at the field of digital cartography and attempt to devise a coordinated and general solution to the problem. The camittee is composed of indivituals fram the Federal, State and local agencies, private enterprise, and the university cammnity. The current members of the Steering Committee are:

Chaiman:

Prof. Harold Moellering, Ohio State University Members:

Mr. Robert Penney, Defense Mapping Agency

Mr. Lawrence Fritz, National Doean Survey

Dr. Richard Durfee, Cak Ridge Laboratories

Dr. Tim Nyerges, Synercam Technology

Mr. Jack Dangemond, Environmental Systems Research Institute

Dr. John Davis, Kansas Geological Survey

Dr. Paula Hagan, Analytical Sciences Corp.

Prof. Ray Boyle, University of Saskatchewan

Prof. Waldo Tobler, University of California

Prof. Dean Merchant, Ohio State University

Prof. Joel Morrisan, University of Wisconsin

Observers:

Mr. Warren Schidt, U.S. Geological Survey

Mr. Lowell Starr, U.S. Geological Survey

Mr. Henry Tom, U.S. Bureau of Standards

Mr. Roy Saltman, U.S. Bureau of Standards

Milton Goldin, U.S. Dept. of Defense

Ex Officio Members:

Mr. Ira Alexander, President, American Congress on Surveying and Mapping

Mr. Steven Vogel, President, American Cartographic Association.

Working Groups for the committee are currently being formed. The overall arganization of the comittee is shown in Figure 1. 


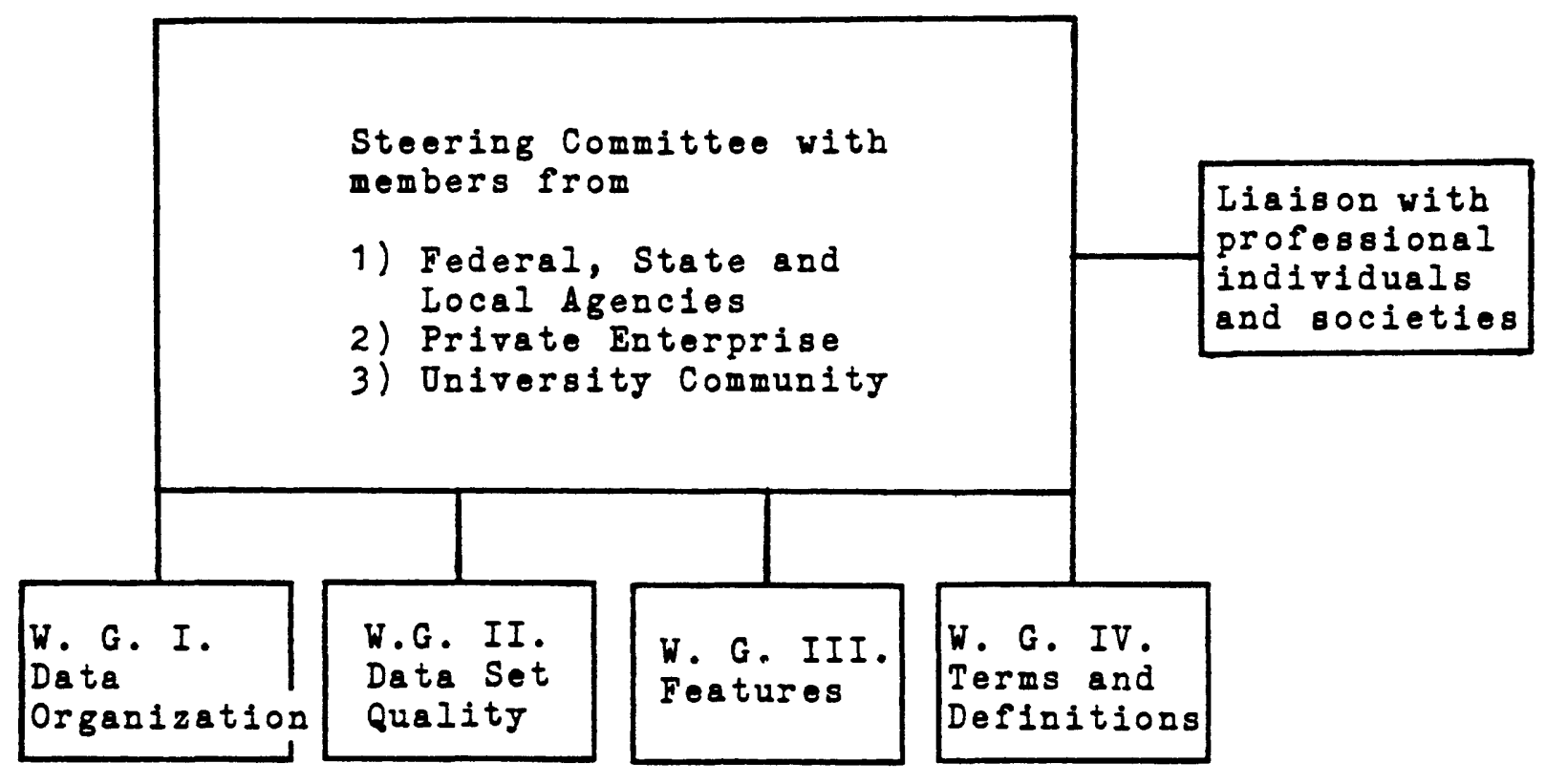

Figure 1. Organization of the National Committee for Digital Cartographic Data Standards

It has been clear to the standards committee that the primary effort of the group should focus on areas which are creating problems for digital cartography. The most pressing current problem in digital cartography is that of incmpatibility between data bases in terms of cata organization, feature classes and codes, cordinate accuracy, metric fidelity, content reliability, and the terms and definitions associated with all of these. Currently such specifications differ widely between data bases which can made the data interchange task extremely difficult. The payoff for the cartographic profession and user community will be that with reasconable standards in these areas, and perhaps in others later, life in our digital world can be much easier and more convenient than it is today. However, in spite of the overwhelming recognition of the need for cartographic standards, there is same concern in the community that someone might attempt to legislate certain kinds of standards which could favor one group over another. This is not the case because the overwhelming opinion of the committee is that any standards specified should be inclusionary rather than exclusionary.

At this point, it is useful to point out two proscriptions that have been defined by the committee. The scope of the committee will not include any standards relating to cartographic comunication nor will it include the specification of the design of particular kinds of cartographic systems. In the first instance, it is felt that cartographic commuication, although a very important area, is really outside 
of the realm of digital cartography as considered for the project at hand. The second proscription has been specified because efficient standards would probably be more general in some ways than those required for specific systems design, but more importantly there is a distinct feeling that one should not disturb the atmosphere which encourages innovation in this area. A third reason is that standards in the area of systems design could create proprietary problems in the private sector of the profession. The comittee also has the distinct feeling that much more innovation and creative development is yet to come in cartographic systems design and specification of standards could be premature at this state of development.

\section{WORKING GROUPS AIREADY DEFTNED}

The fundamental concept underlying the Working Groups (WGs) is the notion that while the broad areas of concern have been specified by the steering comittee, a concerted effort should be made to identify and include the leading experts in cartography to work on the problems assigned to the WG for examination. Again, efforts will be made to maintain the balance between the Federal, State and local agencies, the private sector and academe in the membership of the WGs to the extent possible. The general goals of the WGs are as follows in Table 1.

Table 1. General Goals of the Working Groups

1) To assess the state of current knowledge and understanding in the technical area,

2) Define any gaps in such knowledge and understanding necessary to specify digital cartographic standards in that area,

3) To invite presentations and opinions from all interested parties relating to the standards area,

4) To prepare technical working papers of their deliberations and discussions, and

5) Finally, to propose digital cartographic data standards for its technical area.

The initial stage of this work concerns the enumeration of the issues which relate to the focus of each WG. As each WG proceeds through the process of specifying the important issues in its area, it has been clearly recognized that at this stage of the process it is just as important to specify gaps in our knowledge as it is to specify what we know about a potential problem. If the hGs are systematic in the investigation of gaps in current knowledge, then these findings can be collated, coordinated, and camminicated to the profession as areas requiring further research on a high priority basis.

The deliberations of the comittee to date have resulted in the formation of four Working Groups as shown in Table 2.

Table 2. Working Groups and their tasks

I. Working Group on Data Organization

1) Examine cartographic data models

2) Examine cartographic data structure

3) Examine cartographic data interchange 
II. Working Group on Data Set Duality

1) Fidelity of graphical data, metric and topological

2) Coding reliability

3) Update and other temporal information

4) Iineage of a cata set

5) Checking procedures used by the producer to verify quality

III. Working Group on Features

1) Define feature classes

2) Define structure and levels of classes

3) Define feature codes

IV. Working Group on Terms and Definitions

1) Collect new terms defined by working groups

2) Define other new terms

Working Group on Data Organization

The scope and goals are to identify problems in cartographic data interchange and their consequences at the operational and conceptual levels. The work should concentrate on existing data bases and data models with an enphasis on high speed transfer of, and homeamophisms between, large data bases. The hG should identify terminology and definitions of terms currently being used in the area.

It appears that the most pressing area concerns specifying common data interchange formats so that cartographic information can be converted fram one data base to another. Embedded in that question is the question of cartographic data structure on which much effort has been invested, but which much more work remains to be done in the future. Inbedded in that question is the question of cartographic data models. That question revolves around the situation where there are three primary data models in cartography: hierarchical, network and relational. The question is whether there exists a more general cartographic data model which could act as a covering set for the three listed above. This question is unanswered at the present time. The second question relating to data structure is the fundamental problem of converting data fram ane data structure to another. Although certain transformations, or homeanorphisms, between different data structures are known, many are not, and threfore how they could be specified is unclear. Advanced work on this question could help the profession greatly. The first question of data interchange at its most straightforward level boils down to data interchange formats. Many formats have been tried, and a few have seen limited use between small groups of users, but a general solution has not yet been attempted. A major thrust of this WG will be to examine the possibility of defining a small number of common interchange formats whereby one could easily convert data from one data base to another.

Working Group on Data Set Quality

When one treceives a data set from same source other than ones own organization, in most cases, there are a lot of questions about data set quality which are not easily answered. For example, it is not usually known what the original data source(s) was and what scole(s) the data were gathered. It is usually not known what the original coordinate system was and to what ellipsoid they were associated. The error rates for the coding of substantive data is usually not specified, nor does one know if this data set has ever been updated. There are many 
attributes of a data set which should be made known to the prospective user of that data set which seem to fall into five basic categories: fidelity of graphical data, metric and topological; coding reliability; update and other temporal information; lineage of a data set; and checking procedures used by the producer to verify quality. This sort of infomation would be very informative to the user and indeed be very helpful in deciding whether a particular data set could successfully be used for a particular purpose. The current feeling of the comittee is that what is required is that the producer provide full information about the quality of a data set for the prospective user.

\section{Working Group on Features}

When one picks a feature from some information source such as a map or air photo, there is an immediate problem of the classing system for the feature to be ooded. It turns aut that most agencies have feature classing schemes which are different in structure and content. These incompatibilities are complicated still further because different feature coding schemes are used. The fundamental goal of this WG is to rationalize feature classes used to specify cartographic objects and the hierarchical structure in which they are specified. A rational system of feature codes can then be specified. Specifying a consistent and camprehensive set of feature classes and coojes will be a great boon to the cartographic community.

\section{Working Group on Terms and Definitions}

It is clear that these efforts will unearth terms and definitions which have not been defined in a way which is universally acceptable. Although a fair amount of work had already been expended in procucing the International Cartographic Association glassaries of terms and definitions, there are many terms in numerical and analytical cartography which will be used in this effort which have not been cancisely defined. The goal of this group is to systematically collect and define new terms which relate to these above areas.

\section{Other Possible Working Groups}

The above WGs have been designated as the most important because they will address problems facing the cartographic community. However, there are a number of areas which are candidates for having wGs formed at a later time. They are as follows:

1) Color - a consistent scheme for specifying color and color coordinates in a numerical form which is campatible with conventional printing would be of use to the cammity.

2) Geographical names - a standard set of gecoraphical names would be useful.

3) Test data sets - if one is to have numerical and analytical procedures which are tested and verified, it seems that a common set of test data sets could be very useful.

4) Digitizing standards - these could be of use if they enhance current professional practice. 
5) Digital display standards - they could be of use if they enhance current professional practice.

Other suggestions for potential working Groups will be solicited from the cartographic community.

\section{SIRATEGIES FOR THE STANDARDS PROCESS}

While defining the working groups, the steering camittee has had to grapple with several knotty problems. The first is whether to use an inductive or a deductive approach to each set of tasks. Same members suggested that one should apply all known theory to the problem and work in a top down manner. Others suggested that ane should begin with the operational problems and work in a bottom up mode. Each approach can be rather austere if used alone. However, if one combines both approaches and uses one to challenge the other, then there is a much higher probability that a satisfactory solution can be found. This hybrid approach is being used in all WGs and the membership of each reflects this fact.

It is clear that with the fundamental principles concerning the organization of the camittee as set forth in the second section, and with the camitment to involve the profession in these efforts of consensus building, it becomes evident that the process itself must contain a set of review cycles to solicit direct comment from the profession at large at appropriate times. It seems at the outset that the cycles will occur in the following sequence as shown in Table. 3.

Table 3. Review CYcles for Developing Digital Cartographic Data Standards

1) Define the fundamental issues involved

2) Define the alternatives to the problem

3) Formulate interim proposed standards

4) Reformulate interim proposed standards

5) Generate final proposed standards

At some definite point in each of the five cycles of developing these standards, the current thinking of the WGs and the comittee as a whole will be cammunicated in the form of reports and position papers, and direct comments will be solicited fram the profession. When the situation warrants, the relevant interface area will also be consulted. Such comments, opinions, assessments and proposals will be carefully considered by the proper WG with respect to the merits of the issues involved. This should provide sufficient opportunity for all sides to be heard.

The committee is currently in the midst of cycle ane of defining the fundamental issues involved for each working group. As noted in Table 1 , defining gaps in our knowledge is just as important as defining the issues themselves. This becomes evident when one realizes that in order to properly address the issues later on, one must have sufficient knowledge concerning that issue. If the comittee can efficiently identify the gaps in our knowledge, then it will be possible to go to the cartagraphic research and funding commmity and present these priorities as a challenge for them to address. Hopefully this activity will focus 
such research efforts towards resolving such gaps in our knowledge.

\section{SUMMARY AND CONCLUSION}

With the current situation of a multitude of incompatibilities between approaches to cartographic data organization, data models, data interchange, coordinate and coding specifications, feature classes and codes, it is clear that a move towards a coordinated set of digital cartographic data standards is a step in the right direction. Although the fundamental issues are now only being defined and the major portion of the work is yet to be done, there is a prevailing sentiment that now is the time to begin the process of developing digital cartographic data standards. If efficient solutions to these problems facing the profession can be solved, then such an effort will be of lasting benefit to cartography.

\section{ACKNOWLEDCEMENT}

The work of the National Committee for Digital Cartographic Data Standarts is funded by U.S. Geological Grant \#14-08-0001-G-787.

\section{REFERENCES}

Moellering, H., 1980, "Strategies of Real-Time Cartography," Cartographic Journal, $17(1)$, pp. 12-15.

Moellering, H., 1982, "The Challenge of Developing a Set of National Digital Cartographic Data Standards for the United States," proc. of the ACSM Spring Meetings, Denver, pp. 201-212.

Nyerges, T., 1980, Modeling the Structure of Cartographic Information for ouery Processing, unpublished Ph.D. dissertation, Department of Geography, Ohio State University. 
NATIONAL COMMITTEE FOR DIGITAL CARTOGRAPHIC DATA STANDARDS

Working Group I, Data Organization

Chairman: Dr. Tim Nyerges, Synercom Technology

Members :

Prof. Ray Boyle, University of Saskatchewan

Mr. Marvin White, Bureau of the Census

Dr. Paula Hagan, Wang Laboratories

Mr. Frank Mirkay, Defense Mapping Agency

Mr. William Liles, Technology Service Corp.

Mr. Robin Feagas, Geological Survey

Dr. Donna Peuquet, University of California 
Summary of activities of Working Group I, Data Organization, on Sunday, August 22, 1982, in Washington D.C.

Presented by Dr. Tim Nyerges.

Scope of the Data Organization Working Group:

Working Group I has identified three major sub-issues of Data Organization. They are:

I. Identify terms

a) commonly in use and clearly defined

b) commonly in use but not clearly understood

II. Spatial Data Modeling - focus on conceptual aspects

a) the topic of data structures should be subsumed in spatial data modeling

b) Review of existing spatial data models based in cartographic and mathematical theory

c) Define spatial data model completeness

i. what models are used for specific problems

$i$. What problems can be solved by specific models

III. Data Interchange - what is essential to use data on different systems

a) Review of problems of data interchange

$i$. those previously encountered

ii. any potential problems

b) Look at a generic approach to data interchange

i. problem areas

ii. data components

locational characteristics

non-locational characteristics

topology

iij. Meta-data (data set descriptors/data about data)

The chairman of this Working Group is Dr. Tim Nyerges. 
NATIONAL COMMITTEE FOR DIGITAL CARTOGRAPHIC DATA STANDARDS

Working Group II, Data Set Quality

Coordinator: Mr. Robert Edwards, 0ak Ridge National Laboratories

Members:

Prof. Dean Merchant, Ohio State University

Dr. John Davis, Kansas Geological Survey

Prof. Nicholas Chrisman, University of Wisconsin

$\mathrm{Mr}$. George Rosenfield, Geological Survey

Mr. George Johnson, National Ocean Survey

$\mathrm{Mr}$. Wallace Crisco, Bureau of Land Management 
Summary of activities of Working Group II, Data Set Quality, on Sunday, August 22, 1982, in Washington, D.C.

Presented by Prof. Dean Merchant

The quality report on a cartographic data set is stated at one of five categories, each category including all the components of the previous categories. The first category is simply a structured description of the lineage of the data. At the other extreme the fifth category includes a comparison of the data against an independent source (presumably widely recognized and of unquestionable quality). Here are all five categories:

1. A structured statement of the lineage of the data

2. Add a deductive statement on the expected error

3. Add a statement of the internal error detection and currection performed in conjunction with the collection

4. Add an error analysis of the data as compared with the source material

5. Add an error analysis of the data using an independent source

A cartographic data set is a collection of digital data and consists of one or more cartographic entities:

For example a file of geologic data on petroleum wells

(each well record is a geographic entity)

a file of polygonal boundary segnents approximating a county's boundary

a nierarchical data base of shipping routes for a transportation network (the entire data base might by considered a single cartographic entity)

A cartographic entity is a record of data with attributes and spatial (and possibly temporal) dimensions. The spatial component could be simply a single point, or a set of points. The quality assessinent of a cartographic set is an analysis of the accuracy and completeness of the data in the cartographic entities.

The courdinator for this Working Group is Robert Edwards of Oak Ridge National Laboratories. A permanent chairman will be chosen in the near future. 
NATIONAL CUMITTEE FOR UIGITAL CARTOGRAPHIC DATA STANDARDS

Working Group III, Cartographic Features

Chairman: Prof. Joel Morrison, University of Wisconsin

Menbers:

Mr. Warren Schmidt, Geological Survey

Mr. Robert Jacober, Air Force

Mr. Richard Hogan, National Ocean Survey

Dr. Beth Driver, Technology Service Corp.

Mr. Frederick Tamm-Daniels, Tennessee Valley Authority 
Summary of activities of Working Group III, Cartographic Features, on Sunday, August 22, 1982, in Washington, D.C.

Presented by Prof. Joel Morrison.

Short term objectives:

Examine existing classification of real world features based on federal, state, and local mapping specifications, as well as practices of related professions such as geography, geology, forestry, oceanography, meteorology, etc.

Specific tasks to be done:

1. examine federal, state, and local mapping specifications and agreements

2. examine Canadian Standards for Exchange of digital Cartographic Data

3. list the implications of dealing with "real world" features time and costs.

Issues to be addressed:

1. Scale independence - is it possible - if not, where are the breaks?

2. Organization - hierarchical or something else? depth and level of detail

3. What form of feature definition? separate feature code from attribute code

4. Is there a set of basic cartographic data? What is it?

Next objective (after completion of above)

Take one or two data categories through the envisioned system e.g. coastline definition hydrography landuse/cover

The chairman of this Working Group is Prof. Joel Morrison. 
NATIONAL COMMITTEE FOR DIGITAL CARTOGRAPHIC DATA STANDARDS Working Group IV, Terms and Definitions

Coordinator: Prof. Harold Moellering

Members:

Mr. Dean Edson, E-Quad Systems

Prof. Mark Monmonier, Syracuse University

Mr. Mike Callahan, Geological Survey

$\mathrm{Mr}$. Erich Frey, National Ocean Survey

Dr. Carl Reed III, Autometric Inc. 
Surmmary of activities of Working Group IV, terms and definitions on Sunday, August 22, 1982, in Washington, D.C.

Presented by Dr. Harold Moellering.

The currently identified tasks of the terms working group are:

1. Define digital cartographic data

2. Interact with the other working groups for receiving and sublaitting terins to be defined

3. Compile a list of previously defined terms in standards area:

a) a list of dictionaries and glossaries (approx. $10-20$ )

b) an annotated reference list -- collect information

c) a list of FIPS publications

4. Define cartographic entities (geometric and topological) in 2 and 3 diinensions.

also - look closely at the $8 / 78$ Energy Research Laboraturies Report.

The work of the Terms working group is to be independent of the ICA glossary.

The coordinator for this Working Group is Ur. Harold Moellering. 